\title{
Commercial Washing Detergents-Assisted Alkaline Pretreatment for Lignocellulosic Sugars Production: A First Report
}

\author{
S. Sánchez-Muñoz ${ }^{1}$ E. Mier-Alba ${ }^{1} \cdot$ S. S. da Silva ${ }^{1} \cdot$ A. K. Chandel $^{1}$ (1)
}

Received: 22 December 2020/Accepted: 12 April 2021/Published online: 6 May 2021

(C) Society for Sugar Research \& Promotion 2021

\begin{abstract}
Lignocellulosic sugars are the major renewable building blocks for green fuels and chemicals production. However, the implication of an effective pretreatment process is an inevitable process to access the biomass sugars. Alkaline pretreatment is a viable pretreatment process, causing a selective removal of lignin, with a minimum degradation of carbohydrates, increasing porosity and surface area, eventually enhancing enzymatic hydrolysis. Here, we have assessed commercial cloth washing detergents as catalytic agents, for the lignin removal from sugarcane bagasse. Three different detergents (Brilhiante ${ }^{\circledR}(B)$, Omo ${ }^{\circledR}(O)$, Sabonito Flash ${ }^{\circledR}($ F) $)$ were tested using three different concentrations $(5,10$ and $15 \%)$ with and without $\mathrm{pH}$ adjustment. Pretreatment with $\mathrm{O} 5 \mathrm{pH}(5 \% \mathrm{Omo} \otimes, \mathrm{pH} 12)$ showed the maximum lignin removal $(81.14 \%)$ and retainment of cellulose $(44.15 \%)$, and hemicellulose $(29.71 \%)$ in the pretreated bagasse. The maximum sugars $(26.62 \mathrm{~g} / \mathrm{L})$ were released from the $\mathrm{O} 10 \mathrm{pH}$-pretreated sugarcane bagasse. This study shows the potential of washing detergents as the new potential catalytic agents for the pretreatment of biomass for efficient sugars recovery and retaining maximum lignin in the pretreated substrate.
\end{abstract}

Keywords Sugarcane bagasse - Alkaline pretreatment . Washing detergent $\cdot$ Saccharification .

Second-generation sugars

A. K. Chandel

anuj.kumar.chandel@gmail.com; anuj10@usp.br

1 Bioprocesses and Sustainable Products Laboratory, Department of Biotechnology, Engineering School of Lorena, University of São Paulo (EEL-USP), Lorena, SP 12.602.810., Brazil

\section{Introduction}

The primary source of energy in the world for transportation and materials comes from fossil fuel refinery (Cherubini 2010). Currently, the world demand of fuels is approximately 84 million barrels a day (mb/d) (16 million barrels lower than 2019, because of the impact of COVID19) and is projected to increase by $5.7 \mathrm{mb} / \mathrm{d}$ over the 2019-25 period at an average annual rate of $950 \mathrm{~kb} / \mathrm{d}$ (IEA 2020; EIA 2020). Because of burgeoning oil demand, dwindling prices and geopolitical factors, biomass valorization is an important issue which could be significant in the reduction of the global dependence on fossil fuels (Ferreira 2017). Sugarcane bagasse among the lignocellulosic biomass is among the most promising feedstock in the world for alternative fuels and chemicals production (Sun et al. 2016).

Given that the native form of lignocellulosic biomass is recalcitrant, so pretreatment of biomass an indispensable step before enzymatic hydrolysis to get sugar monomers (Cantero et al. 2019; Brethauer and Studer 2015). Alkaline pretreatment disrupts the hydrogen-bonding network in cellulose and hemicellulose polymers in biomass altering crystallinity, increasing porosity and thus allowing solvent and enzymes to access to the surface and intramolecular areas of biomass (Cantero et al. 2019). Alkaline pretreatment method has emerged as one of the most viable process options due to its selective action on ester linkage breakdown in lignin, fast reaction rates and process simplicity (Kim et al. 2016; Chandel et al. 2019). Alkaline pretreatment selectively removes lignin without degrading many carbohydrates and increases porosity and surface area, thereby enhancing enzymatic hydrolysis (Kim et al. 2016). 
However, the major disadvantage of the alkaline process is the solubilization of considerable amount of lignin which needs to be recovered from the liquor for the energy generation in boilers or subsequent transformation into chemicals (Chandel et al. 2019). Pretreated biomass after enzymatic hydrolysis is then practically insoluble lignin cake accessible for further valorization into fuels and chemicals. Therefore, pretreatment causing specific molecular changes in the biomass rather than solubilization of lignin is an important advantage for reducing the processing cost for lignin recovery, saving of water and energy consumption (Sun et al. 2016; Kim et al. 2016). This concept may play a pivotal role in the lignin valorization within the goals of the sustainable matrix for the development of an advanced biomass-based industry (Beckham et al. 2016). Generally, laundry detergents are made up of builders (50\% weight), surfactants $(15 \%)$, bleach $(7 \%)$, enzymes (2\%), destaining agents, foam formation agents, brighteners, and fragrances (Smulders et al. 2007). Because of these ingredients in detergents, we hypothesized that use of detergents could be potentially applied as a catalytic agent for lignin removal during biomass pretreatment.

The aim of the present work was to evaluate the potential of commercial washing detergents for the enzymatic hydrolysis of lignocellulosic sugars production.

\section{Materials and Methods}

\section{Lignocellulosic Material}

Sugarcane bagasse (SCB) was obtained from Usina Ipiranga Agroindustrial (Descalvado, São Paulo, Brazil). The biomass was air-dried and milled in a Marconi knife mill, model MA 630 (Marconi, São Paulo, Brazil). The milled bagasse was screened using standard Tyler sieves (10 and 14 mesh), and powders were stored at room temperature in a sealed container and used for this study.

\section{Commercial Detergents}

Four commercial detergents (CDs) were purchased from local markets. They are sold in Brazil with the brand name as follows: Brilhiante ${ }^{\circledR}(\mathrm{B})$, Omo ${ }^{\circledR}(\mathrm{O})$, Sabonito Flash ${ }^{\circledR}$ (F).

\section{Commercial Detergents-Assisted Alkaline Pretreatment}

During pretreatment, SCB was subjected to be pretreated by four commercial detergents. Detergents were used in concentrations of 5,10 and $15 \%(\mathrm{w} / \mathrm{v})$. The abovementioned concentrations for pretreatment were performed in combination with autoclaving at $121{ }^{\circ} \mathrm{C}$ under 15 psi for 60 min. All experiments were run with and without $\mathrm{pH}$ adjustment to 12 . The $\mathrm{pH}$ of biomass and detergent solution was adjusted by $4 \mathrm{M} \mathrm{NaOH}$. The ratio of the solid phase to liquid phase in each pretreatment was maintained at 1:10. The pretreated solid biomass was extensively washed with tap water to remove the solubilized lignin and neutralization of it. Biomass was dried at $60{ }^{\circ} \mathrm{C}$ to achieve a constant weight and was subsequently used for enzymatic saccharification.

\section{Enzymatic Hydrolysis}

Pretreated biomass was hydrolyzed using a commercial cellulase complex (CTec $2-0.5 \mathrm{~L}$ ) and was kindly provided by Novozymes Inc., Curitiba, Brazil. Enzymatic hydrolysis was carried out in 50-mL Erlenmeyer flask using enzyme loading of $20 \mathrm{FPU} / \mathrm{g}$ of pretreated SCB at $5 \%$ total solids, $50{ }^{\circ} \mathrm{C}$ for $72 \mathrm{~h}$. The produced hydrolysate was recovered by filtration, and the total reducing sugars concentration was analyzed.

\section{Analytical Methods}

The chemical composition (cellulose, hemicellulose, and lignin) of raw and pretreated SCB was estimated using the protocol described by National Renewable Energy Laboratory-NREL, Colorado, USA (Sluiter et al. 2011). The reducing-sugar content in the enzymatic hydrolysates was determined using the dinitrosalicylic acid method of Miller (1959). Figure 1 presents the flow diagram showing experiments performed to carry out the study.

\section{Results and Discussion}

\section{Effect of Commercial Detergent-Assisted Pretreatments on SCB Composition and Cellulose Availability}

The physicochemical composition of untreated SCB was comprised of $35.4 \pm 1.02 \%$ cellulose, $25.03 \pm 0.82 \%$ of hemicellulose, and $33.9 \pm 1.07 \%$ of lignin on dry weight basis $(97.11 \pm 1.98 \%$ mass balance). Table 1 compares the biomass composition of untreated and detergent pretreated $\mathrm{SCB}$. The maximum increment for cellulose in pretreated samples $(44.7 \pm 2.38 \%)$ was obtained with the detergent $\mathrm{B} 15 \mathrm{pH}$. The $\mathrm{pH}$ adjustment was appeared to be as a major contributing factor in the removal of lignin from native bagasse showing $26.27 \%$ cellulose increase followed by $\mathrm{O} 5 \mathrm{pH}, \mathrm{O} 10, \mathrm{O} 15$ and $\mathrm{O} 15 \mathrm{pH}$, showing increments in available cellulose of $24.71,24,71,23.81$ and $23.19 \%$, respectively (Table 1 ). The results are in accordance with 


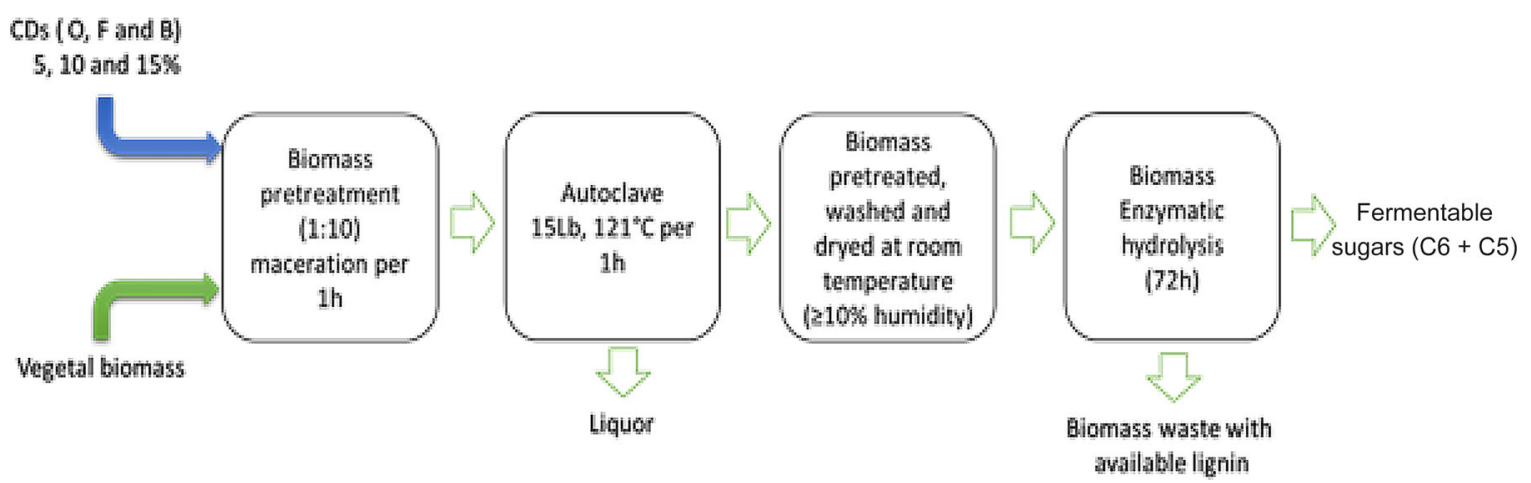

Fig. 1 Detergent-assisted process for lignocellulosic biomass pretreatment

Table 1 Effect of commercial detergents on sugarcane bagasse (SCB) composition \% d.wt (TS—total solids; HC—hydrodynamic cavitation; $\mathrm{pH}-\mathrm{pH}$ adjustment to 12 )

\begin{tabular}{|c|c|c|c|c|}
\hline Biomass pretreatment & Cellulose $(\%)$ & Hemicellulose $(\%)$ & Lignin $(\%)$ & Reference \\
\hline SCB UNTREATED & $35.41 \pm 1.02$ & $25.03 \pm 0.82$ & $33.98 \pm 1.07$ & Current study \\
\hline $\mathrm{SCB}{ }_{\mathrm{B} 15 \mathrm{pH}}$ & $44.70 \pm 2.38$ & $31.09 \pm 2.06$ & $22.26 \pm 0.58$ & \\
\hline $\mathrm{SCB}{ }_{\mathrm{O} 5 \mathrm{pH}}$ & $44.15 \pm 2.72$ & $29.71 \pm 2.02$ & $18.86 \pm 0.41$ & \\
\hline $\mathrm{SCB} 010$ & $44.15 \pm 1.05$ & $32.51 \pm 1.39$ & $25.34 \pm 1.09$ & \\
\hline SCB 015 & $43.83 \pm 0.51$ & $30.26 \pm 1.87$ & $27.08 \pm 1.00$ & \\
\hline $\mathrm{SCB}{ }_{\mathrm{O} 15 \mathrm{pH}}$ & $43.61 \pm 2.68$ & $29.57 \pm 1.86$ & $20.00 \pm 1.90$ & \\
\hline SCB UNTREATED & $44.43 \pm 0.86$ & $22.9 \pm 0.67$ & $17.52 \pm 0.65$ & Maryana et al. (2014) \\
\hline $\mathrm{SCB}$ NaOH $(1 \mathrm{M})-8.3 \%$ TS $100^{\circ} \mathrm{C} / 15 \mathrm{~min}$ & $66.16 \pm 0.13$ & $17.06 \pm 0.4$ & $8.34 \pm 0.35$ & \\
\hline SCB UNTREATED & 40.6 (Glucan) & 26.3 (Xylan) & 24.9 & Hilares et al. (2016) \\
\hline SCB $\mathrm{NaOH}(0.5 \mathrm{M})-6.5 \%$ TS/ 45 min- assisted by $\mathrm{HC}$ & 51.3 (Glucan) & 21.28 (Xylan) & 15.35 & \\
\hline
\end{tabular}

the study of Hilares et al. (2016), showing $26.47 \%$ of available cellulose in the SCB when it was alkaline pretreated by hydrodynamic cavitation. In contrast, Maryana et al. (2014) reported an increment of $48 \%$ of cellulose in the bagasse pretreated with $1 \mathrm{M} \mathrm{NaOH}$ at 1:12 (total solid ratio). Sodium hydroxide is about 2.5 -fold more expensive than commercial detergents (Americanas 2020; Didacticasp 2020; Phlab 2020). In this context, this study shows that the use of detergents, specially $\mathrm{O}$, at 10 and $15 \%$ concentration showed similar cellulose and hemicellulose availability. Even though the lignin removal was not like the typical sodium hydroxide pretreatment (Chen et al. 2011, 2012; Yoon et al. 2011; Loow et al. 2016), it did not decrease the saccharification yield. These results suggest that detergents caused a structural modification in the bagasse cell wall that allowed the cellulases accessibility to the carbohydrates (cellulose and hemicellulose) available in the pretreated bagasse.

\section{Effect of Commercial Detergents on Lignin and Hemicellulose Composition}

Lignin and hemicellulose removal from pretreated biomass increases the amenability of cellulases toward cellulose available in the biomass. The lignin removal from the biomass is an important feature as the lignin devoid substrate yields the sugars without inhibitors after enzymatic hydrolysis (Shen et al. 2012). Typically, lignin percentage after acid or alkaline pretreatment of SCB remains in the range of 15-24\% (Chen et al. 2011, 2012; Yoon et al. 2011; Loow et al. 2016). However, pretreatment conditions employed during the pretreatment play a key role in the extent of delignification of the lignocellulosic substrates. Here, we found that the maximum delignification $(44.5 \%)$ when $5 \%$ of detergent $\mathrm{O}$ was used a catalytic agent with $\mathrm{pH}$ adjustment of 12 by $4 \mathrm{M} \mathrm{NaOH}$. The least amount of lignin removal was observed with detergent $\mathrm{F}$ which showed the lignin removal from 4.55 to $11.05 \%$. Detergents B and A when used with $\mathrm{pH}$ adjustment showed a direct relationship between delignification and detergent concentration. 
Fig. 2 Delignification analysis at different commercial detergents (CDs) concentration with (a) and without (b) $\mathrm{pH}$ adjustment

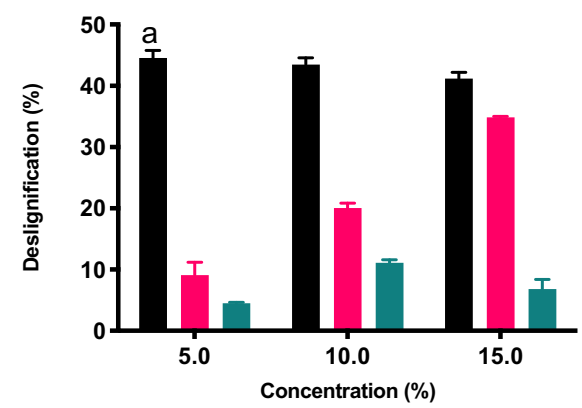

Similarly, Hilares et al. (2016) found that delignification effect was dependent of $\mathrm{NaOH}$ concentration. They observed that maximum lignin removal was reached with $0.5 \mathrm{M}$ of $\mathrm{NaOH}$, followed by 0.3 and $0.1 \mathrm{M}(54.61 \%$, $39.98 \%$ and $32.02 \%$, respectively). In contrast, detergent $\mathrm{O}$ with $\mathrm{pH}$ adjustment showed an inverse effect, where the minimum concentration of detergent led more lignin removal (Fig. 2). Nevertheless, detergents without $\mathrm{pH}$ adjustments did not show any variation in lignin removal at any concentration of detergent.

According to Unilever, the active detergent components in OMO powders are surfactants, such as sodium dodecylbenzenesulfonate. Some OMO detergent powders also

Table 2 Relation between total sugar conversion and total lignin of natural pretreated samples

\begin{tabular}{lll}
\hline Sample & $\begin{array}{l}\text { Total reducing sugars } \\
\text { yield }(\%)\end{array}$ & $\begin{array}{l}\text { Available lignin in the } \\
\text { pretreated bagasse }(\% \mathrm{wt})\end{array}$ \\
\hline Natural bagasse & 14.13 & $33.98 \pm 1.07$ \\
NaOH $0.1 \mathrm{M}$ & 32.49 & $28.63 \pm 0.61$ \\
O5 & 27.78 & $27.05 \pm 0.46$ \\
O5pH & 55.32 & $18.86 \pm 0.41$ \\
O10 & 43.46 & $25.34 \pm 1.09$ \\
O1OpH & 66.5 & $19.22 \pm 0.62$ \\
O15 & 37.20 & $27.08 \pm 1.00$ \\
O15pH & 51.50 & $20.00 \pm 1.90$ \\
B5 & 30.80 & $26.75 \pm 2.08$ \\
B5pH & 59.20 & $30.92 \pm 2.34$ \\
B10 & 25.6 & $26.92 \pm 0.78$ \\
B1OpH & 54.70 & $27.19 \pm 1.48$ \\
B15 & 44.70 & $26.81 \pm 0.18$ \\
B15pH & 57.30 & $22.26 \pm 0.58$ \\
F5 & $13.4 *$ & $30.54 \pm 0.15$ \\
F5pH & 38.6 & $32.45 \pm 0.74$ \\
F10 & $15.05 *$ & $31.23 \pm 0.52$ \\
F10pH & 34.4 & $30.24 \pm 4.33$ \\
F15 & $17.2 *$ & $30.22 \pm 1.58$ \\
F15pH & 33.78 & $31.70 \pm 1.21$ \\
\hline It is & $50 m e d t 5$ &
\end{tabular}

*It is inferred that some detergent components interfered in the saccharification process and analysis protocols for sugars contain lipase, amylase and other enzymes that help break down protein-based stains. Sodium compounds, such as sodium carbonate and sodium sulfate, are common building and bulking agents in these formulations. These agents comprise most of the actual mass of the powder. Other binding agents, and stabilizers, such as cellulose, sodium polyacrylate and tetrasodium etidronate, ensure that the components of the detergent remain well-mixed. This information could have several modifications depending on the region, and regulations for each country, other detergents used in the current work could contain similar compositions and the variation of the quality of each component could depend on the brand and cost of the product.

In regard to the hemicellulose removal, all pretreatment conditions showed an increment in its content in the pretreated bagasse. When $\mathrm{pH}$ was adjusted, the range of hemicellulose increment had a variation between 7.83 and $24.21 \%$, but when $\mathrm{pH}$ was not adjusted, the increment of this fraction was between 9.34 and $29.88 \%$. Some reports in literature indicated that the use of $\mathrm{NaOH}$ in pretreatment tends to remove lignin and hemicellulose (de Carvalho et al. 2016; Ascencio et al. 2019). However, we found in the in the current results, the use of some commercial detergents allows to enhance cellulose and hemicellulose in the pretreated SCB as shown in pretreatments in Table 1, even without high levels of delignification. During the pretreatment, the retainment of maximum carbohydrates in the biomass is an advantageous strategy to get high sugars concentration after enzymatic hydrolysis (Ascencio et al. 2019; Adsul et al. 2020).

\section{Effect of Recalcitrant Lignin on Enzymatic Saccharification}

The effect of the detergents-assisted pretreatment showed different responses on sugars release after enzymatic hydrolysis. Sugars recovery predominantly depends on the amount of lignin in pretreated substrate. Lignin is considered the most important factor in the accessibility of cellulases to the cellulose in the substrate (Kim et al. 2016). Detergents did not remove a very high amount of lignin 

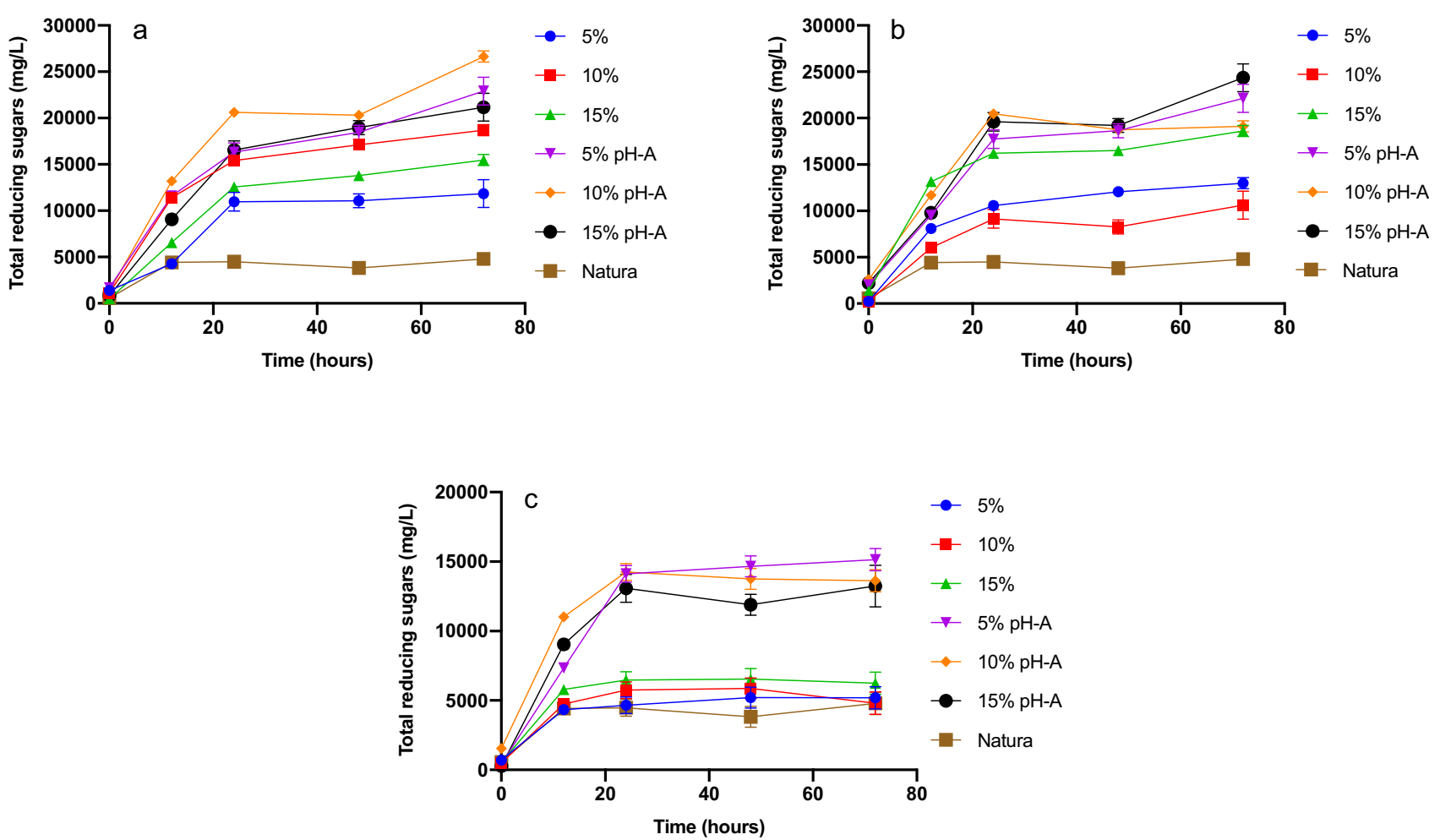

Fig. 3 Reducing sugar release kinetics of detergent pretreated sugarcane biomass after enzymatic hydrolysis

from the substrate but might have caused changes in the cellulose-lignin network at molecular level. Table 2 shows the amount of lignin in all detergents pretreated bagasse samples. This is evident with the table that approximately $18-25 \%$ of lignin was removed from the native bagasse after pretreatment with all three detergents used in the study. Detergent $\mathrm{O}$ after $\mathrm{pH}$ adjustment of 12 caused maximum lignin removal (Table 2), which in turn showed the higher sugar recovery (50-67\%) after enzymatic hydrolysis. Ladeira et al. (2020) found $22 \%$ lignin in the liquid hot water-pretreated SCB showing 52\% of glucose yield after enzymatic hydrolysis. Seo et al. (2017) observed $67 \%$ lignin removal from lignocellulose after a mixed pretreatment with acids and surfactants. The pretreated biomass when enzymatically hydrolyzed showed $6 \mathrm{~g} / \mathrm{l}$ sugars (21\% yield), while Maheswari et al. (2020) found saccharification yields of $28 \%$ on SCB with alkali pretreatment and $33 \%$ for assisted alkali pretreatment with humic acid and $\mathrm{CaCl}_{2}$ (5\% of improvement). In the current study, detergents F5- and F10-pretreated SCB showed similar results like $\mathrm{NaOH}$-pretreated SCB.

Maximum sugars were obtained from the SCB after pretreatment with detergents $\mathrm{B}$ and $\mathrm{F}$.

Detergent $\mathrm{F}$ presented similar results in every concentration tested, yielding high sugar recovery with the available lignin, $13-17 \mathrm{~g} / \mathrm{L}$ and $30-33 \%$, respectively (Fig. 3). The best results are considered those that released the highest amounts of reducing sugar while maintaining the highest amount of lignin. B5pH-based pretreatment had the best performance releasing the highest amount of sugar $(59.20 \%, 22.13 \mathrm{~g} / \mathrm{L})$ and retaining $30.92 \%$ of lignin. This is important feature in recovering the high amount of sugars $(59.2 \%, 22.13 \mathrm{~g} / \mathrm{l})$ while retaining considerably high amount of lignin in the substrate indicating the potential of residual solids for new applications in biorefinery after the sugars extraction. The high amount of lignin in the hydrolyzed substrate could be valorized for the adhesives, resins and important phenolic compounds in biorefinery (Garlapati et al. 2020).

Pretreatments of $\mathrm{SCB}$ at $\mathrm{B} 10 \mathrm{pH}, \mathrm{B} 15$ and $\mathrm{B} 15 \mathrm{pH}$ released $44-57 \%$ reducing sugars with the retainment of $22-29 \%$ of residual lignin. Pretreatment conditions (F5pH, $\mathrm{F} 10 \mathrm{pH}$ and $\mathrm{F} 15 \mathrm{pH}$ ) showed $33-39 \%$ of reducing sugars release, with 30-33\% residual lignin in the pretreated SCB. Similar glucose yields were as reported by Seo et al. (2017) after surfactant-based pretreatment of SCB. The role of catalytic agents in biomass pretreatment is pivotal for the lignocellulosic sugars recovery after enzymatic hydrolysis. For instance, Rabeya et al. (2020) observed $61.75 \%$ and $71.49 \%$ degradation of hemicellulose and lignin, respectively, after $2 \% \mathrm{NaOH}$ pretreatment of corn stalk at $100{ }^{\circ} \mathrm{C}$ for $1 \mathrm{~h}$. Sodium hydroxide acts on lignin removal from the lignocellulosic substrate leaving cellulose and lignin together improving the amenability of cellulolytic enzymes 
for renewable sugars production. On the other hand, dilute sulfuric acid pretreatment mechanistically acts on hemicellulose degradation from the lignocellulosic substrate. For example, sugarcane straw pretreatment by sulfuric acid pretreatment $\left(130{ }^{\circ} \mathrm{C}, 2.9 \% \mathrm{w} / \mathrm{v} \mathrm{H}_{2} \mathrm{SO}_{4}\right.$ solution, solidliquid ratio (1:4) and $30 \mathrm{~min}$ of residence time) showed a xylose concentration of $56.5 \mathrm{~g} / \mathrm{l}$ (Moutta et al. 2012).

The choice of treatment will depend on the process to be coupled or the subsequent use of biomass, depending on which of the two fractions (sugars or lignin) will be used in a greater proportion.

\section{Conclusion}

Alkaline pretreatment has been considered one of the most effective methods for the cellulosic sugars production. Our results clearly indicate that pretreatment of lignocellulosic biomass with commercial detergents followed by enzymatic hydrolysis greatly enhances the enzymatic conversion of carbohydrate polymers into fermentable sugars. These results also support the possibility of retaining residual lignin in the pretreated biomass while yielding the high amount of sugars after enzymatic hydrolysis. Commercial detergent-assisted pretreatment provides an alternative strategy for pretreatment of vegetal biomass and presents a new sustainable application of detergents in economic $2 \mathrm{G}$ sugars production which can be used as an excellent feedstock in biorefineries for the biofuels, biochemicals and biomaterials production.

Funding Funding was received from Coordenação de Aperfeiçoamento de Pessoal de nivel Superior (CAPES), CNPq Conselho Nacional de Desenvolvimento Científico e Tecnológico (CNPq), and Fundação de Amparo à Pesquisa do Estado de São Paulo FAPESP (Brazilian Government funding agencies) and Consejo Nacional de Ciencia y Tecnología (CONACyT).

Availability of data and material The data have been originated from the experiments. Sugarcane bagasse was collected locally, cellulase was gifted from Novozymes Inc, Curitiba, Brazil, and commercial detergents were procured from local market

\section{Declarations}

Conflicts of interest All authors declare no conflicts of interest.

Consent to participate All authors have consented their participation

Consent for publication All authors have consented the publication of this work.

\section{References}

Adsul, M., S.K. Sandhu, R.R. Singhania, R. Gupta, S.K. Puri, and A. Mathur. 2020. Designing a cellulolytic enzyme cocktail for the efficient and economical conversion of lignocellulosic biomass to biofuels. Enzyme and Microbial Technology 133: 109442. https://doi.org/10.1016/j.enzmictec.2019.109442.

Ascencio, J.J., A.K. Chandel, R.R. Philippini, and S.S. Silva. 2019. Comparative study of cellulosic sugars production from sugarcane bagasse after dilute nitric acid, dilute sodium hydroxide and sequential nitric acid-sodium hydroxide pretreatment. Biomass Conversion and Biorefinery 10: 813-822. https://doi.org/10.10 07/s13399-019-00547-6.

Americanas. 2020. Detergente Omo. https://www.americanas.com.br /busca/detergente-omo. Accessed: 04 August 2020

Brethauer, S., and M.H. Studer. 2015. Biochemical conversion processes of lignocellulosic biomass to fuels and chemicals A review. Chimia (Aarau) 69: 572-581. https://doi.org/10.2533/ chimia.2015.572.

Cantero, D., R. Jara, A. Navarrete, L. Pelaz, J. Queiroz, S. RodriguézRajo, and M.J. Cocero. 2019. Pretreatment processes of biomass for biorefineries: Current status and prospects. Annual Reviews in Chemical Biomolecular Engineering 10: 289-310. https://doi.org/10.1146/annurev-chembioeng-060718-030354.

Chen, W.S., Y.J. Tu, and H.K. Sheen. 2011. Disruption of sugarcane bagasse lignocellulosic structure by means of dilute sulfuric acid pretreatment with microwave-assisted heating. Applied Energy 88: 2726-2734. https://doi.org/10.1016/j.apenergy.2011.02.027.

Chen, W.S., S.C. Ye, and H.K. Sheen. 2012. Hydrolysis characteristics of sugarcane bagasse pretreated by dilute acid solution in a microwave irradiation environment. Applied Energy 93: 237-244. https://doi.org/10.1016/j.apenergy.2011.12.014.

Cherubini, F. 2010. The biorefinery concept: using biomass instead of oil for producing energy and chemicals. Energy Conversion and Management 51: 1412-1421. https://doi.org/10.1016/j.enconma n.2010.01.015.

Beckham, G.T., C.W. Johnson, E.M. Karp, and D. Salvachúa D, and D.R. Vardon. . 2016. Opportunities and challenges in biological lignin valorization. Current Opinion in Biotechnology 42: 40-53. https://doi.org/10.1016/j.copbio.2016.02.030.

De Carvalho, D.M., J.H. de Queiroz, and J.L. Colodette. 2016. Assessment of alkaline pretreatment for the production of bioethanol from eucalyptus, sugarcane bagasse and sugarcane straw. Industrial Crops and Products 94: 932-941. https://doi.org/10.1016/j.indcrop.2016.09.069.

Didactica S.P. 2020. Hidroxido de sodio micropérolas pa. https://www.didaticasp.com.br/hidroxido-de-sodiomicroperolas-pa-1kg-pfssp. Accessed: 04 August 2020

Energy Information Administration (EIA). 2020. Short-term energy outlook: Global liquid fuels. https://www.eia.gov/outlooks/steo/ report/global_oil.php. Accessed 13 September 2020

Ferreira, A. F. 2017. Biorefinery concept. In Biorefineries, ed. Z. Guangyin, and Z. Youcai, 181-273, Cham: Springer Publications. 2017.

Garlapati, V.K., A.K. Chandel, S.P.J. Kumar, S. Sharma, S. Sevda, A.P. Ingle, and D. Pant. 2020. Circular economy aspects of lignin: Towards a lignocellulose biorefinery. Renewable and Sustainable Energy Reviews 130: 109977. https://doi.org/10.10 16/j.rser.2020.109977.

Hilares, R.T., J.C. dos Santos, M.A. Ahmed, S.H. Jeon, S.S. da Silva, and J.I. Han. 2016. Hydrodynamic cavitation-assisted alkaline pretreatment as a new approach for sugarcane bagasse biorefineries. Bioresource Technology 214: 609-614. https://doi. org/10.1016/j.biortech.2016.05.004. 
International Energy Agency (IEA). (2020). Oil 2020: Fuel report March 2020. https://www.iea.org/reports/oil-2020. Accessed 13 September 2020

Kim, J.S., Y.Y. Lee, and T.H. Kim. 2016. A review on alkaline pretreatment technology for bioconversion of lignocellulosic biomass. Bioresource Technology 199: 42-48. https://doi. org/10.1016/j.biortech.2015.08.085.

Chandel, A.K., J.Q. Albarelli, D.T. dos Santos, S.P.S. Chundawat, M. Puri, and M.A.A. Meireles. 2019. Comparative analysis of key technologies for cellulosic ethanol production from Brazilian sugarcane bagasse at the commercial-scale. Biofuels, Bioproducts and Biorefining 13: 994-1014.

Ladeira Ázar, R.I., S.E. Bordignon-Junior, C. Laufer, J. Specht, D. Ferrier, and D. Kim. 2020. Effect of lignin content on cellulolytic saccharification of liquid hot water pretreated sugarcane bagasse. Molecules 25: 623. https://doi.org/10.3390/ molecules 25030623

Loow, Y., T.Y. Wu, JMd. Jahim, A.W. Mohammad, and W.H. Teoh. 2016. Typical conversion of lignocellulosic biomass into reducing sugars using dilute acid hydrolysis and alkaline pretreatment. Cellulose 23: 1491-1520. https://doi.org/10.1007/s10570-016-0 936-8.

Maheswari, R.U., M.O. Mavukkandy, U. Adhikari, V. Naddeo, J. Sikder, and H.A. Arafat. 2020. Synergistic effect of humic acid on alkali pretreatment of sugarcane bagasse for the recovery of lignin with phenomenal properties. Biomass and Bioenergy 134: 105486. https://doi.org/10.1016/j.biombioe.2020.105486.

Maryana, R., D. Ma'rifatun, A.I. Wheni, K.W. Satriyo, and W.A. Rizal. 2014. Alkaline pretreatment on sugarcane bagasse for bioethanol production. Energy Procedia 47: 250-254. https://doi.org/10.1016/j.egypro.2014.01.221.

Miller, G.L. 1959. Use of dinitrosalicylic acid reagent for determination of reducing sugar. Anal. Chem. 31: 426-428.

$\mathrm{Ph}$ Lab. 2020. Hidroxido de sodio pa. https://www.phlab.com.br/ produto/hidroxido-de-sodio-pa-acs-frasco-1-kg/. Accessed: 04 August 2020
Seo, D.J., H. Fujita, and A. Sakoda. 2011. Effects of a non-ionic surfactant, Tween /desorption of saccharification enzymes onto/ from lignocelluloses and saccharification rate. Adsorption 17: 813-822. https://doi.org/10.1007/s10450-011-9340-8

Shen, F., J. Hu, Y. Zhong, M.L. Liu, J.N. Saddler, and R. Liu. 2012. Ethanol production from steam-pretreated sweet sorghum bagasse with high substrate consistency enzymatic hydrolysis. Biomass and Bioenergy 41: 157-164. https://doi.org/10.1016/ j.biombioe.2012.02.022.

Sluiter, A. et al. 2011. NREL determination of structural carbohydrates and lignin in biomass. NREL/TP-510-42618. National Renewable Energy Laboratory, Golden. Technical report

Smulders, E., W. von Rybinski, E. Sung, W. Reahse, J. Steber, F. Wiebel, A. Nordskog. 2007. Laundry detergents. In: Ullmann's Encyclopedia of Industrial Chemistry

Sun, S., S. Sun, X. Cao, and R. Sun. 2016. The role of pretreatment in improving the enzymatic hydrolysis of lignocellulosic materials. Bioresource Technology 199: 49-58. https://doi.org/10.1016/ j.biortech.2015.08.061.

Yoon, L.W., G.C. Ngoh, A.S.M. Chua, and M.A. Hashim. 2011. Comparison of ionic liquid, acid and alkali pretreatments for sugarcane bagasse enzymatic saccharification. Journal of Chemical Technology Biotechnology 86: 1342-1348. https://doi.org/ 10.1002/jctb.2651.

Rabeya, T., F. Jehadin, M.A. Asad, O.O. Ayodele, A.E. Adekunle, and M.S. Islam. 2020. Alkali and intensified heat treatment of corn stalk for bioethanol production. Sugar Tech. https://doi.org/10.1007/s12355-020-00908-w.

Moutta, R.O., A.K. Chandel, R.C.L.B. Rodrigues, M.B. Silva, G.J.M. Rocha, S.S. da Silva, and S.S. . 2012. Statistical optimization of sugarcane leaves hydrolysis into simple sugars by dilute sulfuric acid catalyzed process. Sugar Tech 14: 53-60. https://doi.org/10.1007/s12355-011-0116-y.

Publisher's Note Springer Nature remains neutral with regard to jurisdictional claims in published maps and institutional affiliations. 